\title{
Computed Tomography Evaluation of the Brain and Upper Cervical Spine in Patients With Traumatic Cardiac Arrest Who Achieved Return of Spontaneous Circulation
}

\author{
Joji INAMASU, ${ }^{1,2}$ Masashi NAKATSUKASA, ${ }^{2}$ and Yuichi HIROSE ${ }^{1}$ \\ ${ }^{1}$ Department of Neurosurgery, Fujita Health University School of Medicine, Toyoake, Aichi; \\ ${ }^{2}$ Department of Neurosurgery, Saiseikai Utsunomiya Hospital, Utsunomiya, Tochigi
}

\begin{abstract}
The outcomes of patients with traumatic cardiac arrest (TCA) have been dismal. However, imaging modalities are improving rapidly and are expected to play a role in treatment of patients with TCA. In this retrospective study, whether obtaining computed tomography (CT) immediately after resuscitation had any clinical value was evaluated. Among 145 patients with TCA admitted to our institution during 4 years, hemodynamically stable return of spontaneous circulation (ROSC) was achieved in $38(26 \%)$. Brain and cervical spine CT was obtained prospectively, and the frequency and type of traumatic brain injury (TBI)/upper cervical spine injury (UCSI) were investigated. CT was performed uneventfully in all patients with an average door-to-CT time of $51.5 \pm 18.6 \mathrm{~min}$. Twenty $(53 \%)$ had CT evidence of TBI. However, no patients underwent brain surgery because of lack of return of brainstem functions. Among the 18 patients without TBI, CT signs of hypoxia were present in 15 patients $(39 \%)$, and CT was considered intact in 3 patients $(8 \%)$. None of the 35 patients with abnormal CT findings survived, and the presence of such findings predicted fatality with high sensitivity and specificity. While 13 of the 38 patients (34\%) had CT evidence of UCSI, concomitant TBI and USCI were uncommon. None of the 13 patients with UCSI underwent spine surgery because of lack of return of brainstem functions, and the presence of USCI might also be associated with fatality. Although obtaining CT was useful in the prognostication of TCA patients with ROSC, it did not have much impact in therapeutic decision making.
\end{abstract}

Key words: computed tomography, return of spontaneous circulation, traumatic brain injury, traumatic cardiac arrest, upper cervical spine injury

\section{Introduction}

Prognosis for patients with traumatic cardiac arrest (TCA) has been dismal. ${ }^{13,18)}$ Majority of the patients die at the scene or in the emergency department (ED) without establishment of return of spontaneous circulation (ROSC). ${ }^{13,18)}$ Furthermore, even those who achieve ROSC in the ED rarely achieve longterm survival. ${ }^{13,18)}$ However, vigorous resuscitative efforts initiated at the scene seem to improve their outcomes, and clinical variables predictive of longterm survival have been identified. ${ }^{4,8,16)}$ Recently, the role of brain computed tomography (CT) in the resuscitation of patients with non-traumatic cardiac arrest (CA) has been established. ${ }^{5,10,11,15)}$ Whole body CT scans may also have an important role in the

Received July 9, 2012; Accepted December 11, 2012 acute care of poly-trauma patients presenting with pulse. ${ }^{9)}$ However, few researchers have evaluated the role of brain and cervical spine CT in the acute care of patients with TCA. CT scans are obtained immediately after achievement of ROSC from patients with CA of any etiologies in our institution, ${ }^{10,11)}$ and a retrospective study is conducted to clarify whether obtaining CT scans has a role in the prognostication of patients with TCA.

\section{Patients and Methods}

This study was conducted from July 2006 to June 2010 in a single institution, which is a tertiary referral center covering a local population of approximately 500,000. Cardiopulmonary resuscitation (CPR) for adult patients with TCA was performed following the advanced trauma life support guidelines. ${ }^{19)}$ No patients with TCA underwent an emergency thoracotomy or 
chest tube insertion at the scene. As soon as the patients were brought to the ED, they underwent focused ultrasound of the chest and abdomen during resuscitation. Immediately after successful CPR and achievement of ROSC, they were brought to a CT suite adjacent to the ED, on the condition that their blood pressure (BP) was stable enough for transport. The CT suite was equipped with a Light-Speed 16-detector row CT scanner (GE Healthcare, Tokyo), and helical CT of the brain and cervical spine was obtained. Patients with penetrating TCA as well as pediatric patients with TCA $(<15$ years of age) were excluded from analysis. All CT images were stored and viewed with picture archiving and communication systems. Presence and type of brain injury/ upper cervical spine injury (UCSI) was evaluated by a board-certified neurosurgeon who was unaware of each patient's condition. For evaluation of UCSI, 3-dimensional reconstruction of the CT images of the cervical spine was available in all subjects. Patients were classified according to the presence of traumatic brain injury (TBI) on brain CT. Those without a CT evidence of TBI were further classified depending on the presence of early CT signs of hypoxic brain injury. The definition of CT signs of hypoxic brain injury, including (1) loss of boundary between the gray matter and white matter and (2) presence of cortical sulcal effacement sign, is based on the study by Torbey et al. ${ }^{21)}$ Subsequently, the frequency and type of UCSI were investigated and relationship between TBI and UCSI was evaluated. Autopsy of those who died in the ED or during hospitalization was not performed routinely.

\section{Results}

\section{Demographics}

During the 4-year period, 145 patients with CA due to blunt trauma were brought to our ED. One hundred and sixteen (80\%) patients were already pulseless at the scene, while the other $29(20 \%)$ became pulseless during transfer to or shortly after ( $<15 \mathrm{~min}$ ) arrival at our ED. ROSC and stable BP was established in $38(26 \%)$. Brain and cervical spine CT were obtained uneventfully from all patients. ED door-to-CT time ranged from $21 \mathrm{~min}$ to $100 \mathrm{~min}$, with an average of $51.5 \pm 18.6 \mathrm{~min}$, and CT was completed within 60 min of ED arrival in 25 patients (66\%). Injury severity score ranged from 16 to 64 (mean: $34.3 \pm 10.5$ ). Survival period ranged from 1 to 452 days (mean: $11.7 \pm 59.0$ days). Twenty-seven patients $(71 \%)$ died within $24 \mathrm{~h}$ of admission. The results are summarized in Table 1.
Table 1 Demographics of 38 traumatic cardiac arrest patients who achieved return of spontaneous circulation

\begin{tabular}{ll}
\hline Age (yrs) & $16-91$ (mean: $55.4 \pm 22.8$ ) \\
M:F & $32: 6$ \\
Mechanism of injury & $\begin{array}{l}\text { Motor vehicle accident: 29, } \\
\text { Fall: 8, Assault: } 1\end{array}$ \\
ISS & $16-64$ (mean: $34.3 \pm 10.5$ ) \\
ED door-to-CT time & $21-100$ (mean: $51.5 \pm 18.6$ ) \\
(min) & \\
Mean survival (day) & $\begin{array}{l}1-452 \text { (mean: } 11.7 \pm 59.0, \\
\text { median: } 1)\end{array}$ \\
\hline
\end{tabular}

CT: computed tomography, ED: emergency department, ISS: Injury Severity Score.

Table 2 Type and frequency of traumatic brain/upper cervical spine injury

\begin{tabular}{ll}
\hline \multicolumn{1}{c}{ TBI $(\mathrm{N}=20)$} & \multicolumn{1}{c}{ UCSI $(\mathrm{N}=13)$} \\
\hline $\begin{array}{l}\text { Diffuse swelling with } \\
\text { hemorrhage: } 19\end{array}$ & C2 odontoid fracture: 6 \\
ASDH with midline shift: 4 & AAD: 4 \\
Skull fracture: 17 & OAD: 2 \\
& C2-3 fracture-dislocation: 1 \\
\hline
\end{tabular}

AAD: atlanto-axial dislocation, ASDH: acute subdural hematoma, OAD: occipito-atlantal dislocation, TBI: traumatic brain injury, USCI: upper cervical spine injury.

\section{Frequency and type of brain injury}

Twenty patients $(53 \%)$ had a CT evidence of TBI. Diffuse hemorrhagic brain swelling was seen in 19 patients (Table 2). On the other hand, acute subdural hematoma with midline shift $(>5 \mathrm{~mm}$ ) was present only in 4 patients. Skull fractures were present in 17 patients. Among the 18 patients without TBI, early CT signs of hypoxia were present in 15 $(39 \%)$, and in the other 3 patients $(8 \%)$, brain CT was considered intact (Fig. 1). As a consequence, a total of 35 patients (92\%) were considered to have abnormal brain CT (Fig. 1). None of the 20 patients with TBI or 15 with hypoxic brain injury recovered brainstem functions and survived to discharge, and brain surgery was performed in none of them. By contrast, one of the 3 patients with intact brain CT survived to discharge. As a result, one of the 38 patients $(3 \%)$ achieved a longterm survival, and the overall survival rate of TCA patients in our institution was $0.7 \%$ ( 1 in 145). The presence of abnormal brain CT predicted fatality with a sensitivity of $95 \%$, specificity of $100 \%$, and positive predictive value of $100 \%$. Cases with a typical CT finding of TBI and hypoxic brain injury is illustrated in Fig. 2. 


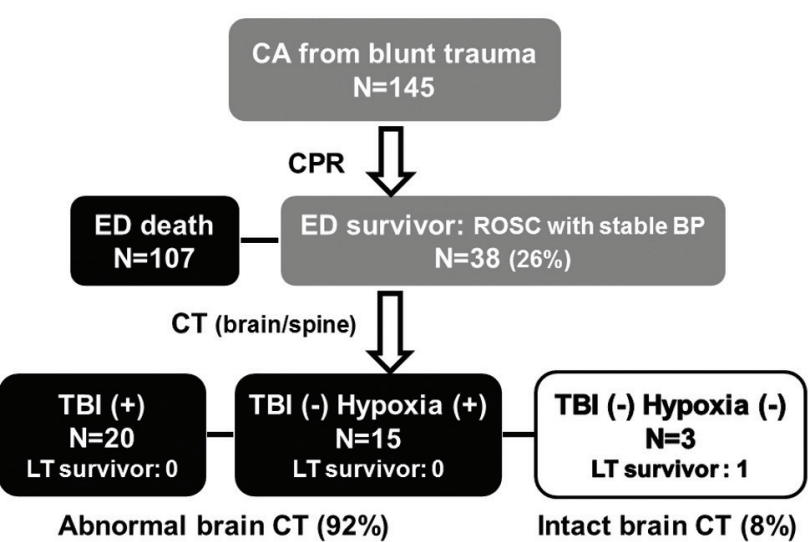

Fig. 1 Outcomes of 38 patients classified by brain computed tomography (CT) findings are shown. BP: blood pressure, CA: cardiac arrest, ED: emergency department, LT: long-term, ROSC: return of spontaneous circulation, TBI: traumatic brain injury.

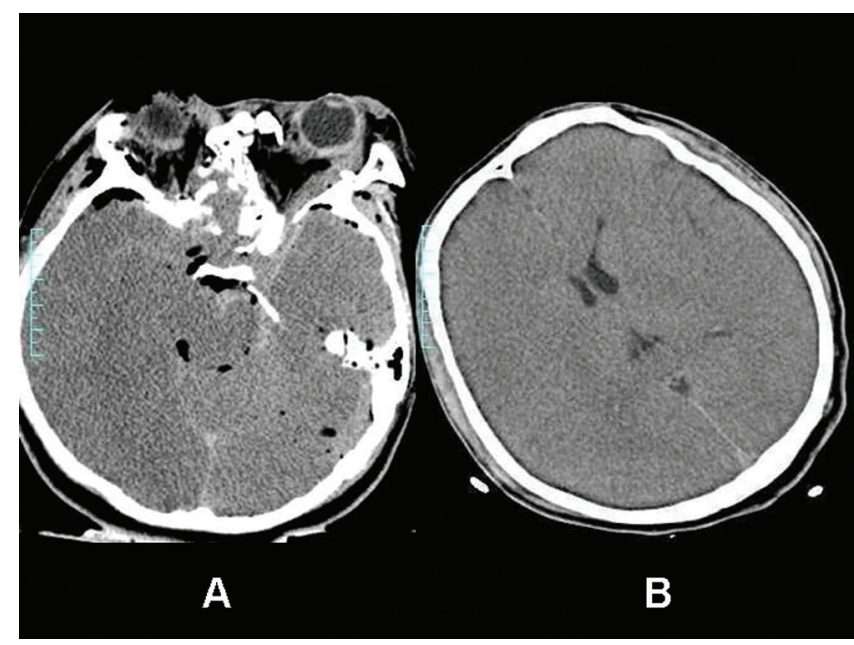

Fig. 2 A: A case of traumatic brain injury, characterized by diffuse traumatic subarachnoid hemorrhage, intracranial air, and destruction of the anterior skull base. B: A case of hypoxic brain injury, characterized by loss of boundary between the gray matter and white matter and cortical sulcal effacement.

\section{Frequency and type of UCSI}

Among the 38 patients, $13(34 \%)$ had a CT evidence of UCSI. The types of USCI in order of frequency were: C2 odontoid fractures in $6(16 \%)$, atlanto-axial dislocations (AAD) in $4(11 \%)$, occipitoatlantal dislocations (OAD) in $2(5 \%)$, and $\mathrm{C} 2-\mathrm{C} 3$ fracture-dislocation in 1 (3\%) (Table 2). A case with an $\mathrm{OAD}$ and a case with a $\mathrm{C} 2$ odontoid fracture is

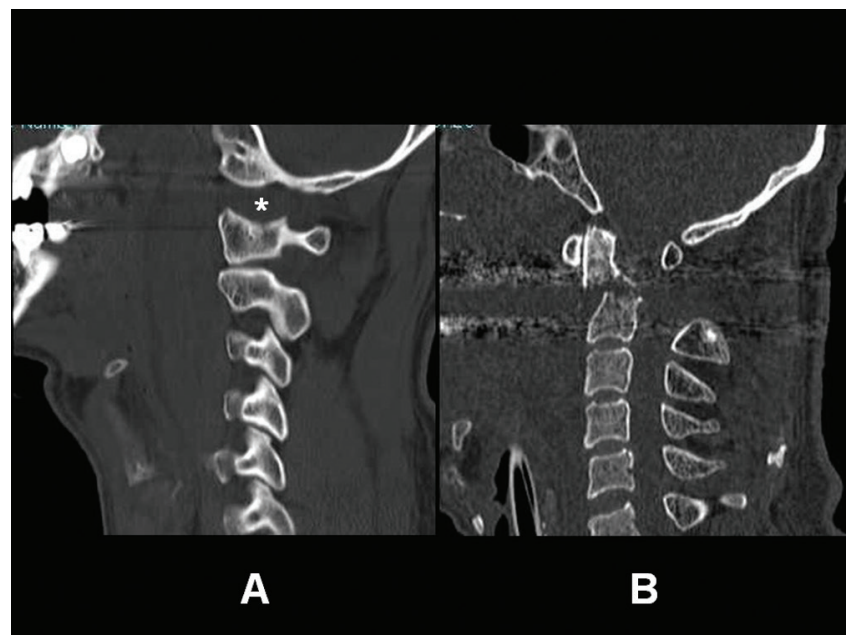

Fig. 3 A: A case of occipito-atlantal dissociation. Marked distraction of the occipito-atlantal joint is indicated with an asterisk. B: A case of C2 odontoid fracture with marked dislocation.

Table 3 Relationship between traumatic brain injury and upper cervical spine injury

\begin{tabular}{ccc}
\hline \multirow{2}{*}{ TBI } & \multicolumn{2}{c}{ UCSI } \\
\cline { 2 - 3 } & Yes & No \\
\hline Yes & $5(13 \%)$ & $15(40 \%)$ \\
No & $8(21 \%)$ & $10(26 \%)$ \\
\hline
\end{tabular}

TBI: traumatic brain injury, UCSI: upper cervical spine injury.

illustrated in Fig. 3. None of the 13 patients with UCSI recovered brainstem functions and survived to discharge, and spine surgery was performed in none of them. Subsequently, relationship between TBI and UCSI is shown in $2 \times 2$ Table (Table 3 ). Five patients $(13 \%)$ had concomitant TBI and USCI, $15(40 \%)$ had TBI alone, $8(21 \%)$ had USCI alone, and the other $10(26 \%)$ had neither TBI nor USCI.

\section{Discussion}

A pessimistic view that CPR might be futile for patients with TCA had prevailed because of their poor prognosis. ${ }^{13,18)}$ However, vigorous resuscitation initiated at the scene seems to improve their outcomes. ${ }^{4,8,16)}$ Recent studies showed that the longterm survival rate of patients with TCA improved to $9-17 \% .^{4,8,16)}$ Several prognostic variables have been reported, including presence of pulse and reactive pupil at the scene., ${ }^{4,8,16)}$ Other than such vital signs, however, diagnostic adjuncts used in comatose patients to evaluate survivability, such as electroencephalogram and brainstem auditory 
evoked potentials, may not be available or reliable in ED or intensive care unit. ${ }^{2)}$ Recently, the role of imaging studies in the treatment of patients with non-traumatic CA seems to have been established..$^{5,10,11,15)}$ Brain CT occasionally revealed an unexpected intracranial hemorrhage which was responsible for CA. ${ }^{5,10,15)}$ Early CT signs of hypoxic brain injury were present in as many as $70 \%$ of nontraumatic CA patients with ROSC, ${ }^{11)}$ and presence of intracranial hemorrhage and/or hypoxic brain injury almost invariably predicted fatality in that population. ${ }^{10,11)}$ Similarly, the use of whole body CT in the acute care of poly-trauma patients presenting with pulse significantly increased the probability of long-term survival. ${ }^{9)}$ However, few authors have evaluated the role of CT during resuscitation of patients with TCA.

In this study, CT was feasible in all of the 38 TCA patients achieving ROSC with an average ED door-to-CT time of $51.5 \pm 18.6 \mathrm{~min}$. CT evidence of TBI was present in 53\%. Interestingly, only a small fraction of patients with TBI had CT evidence of brain herniation (Table 2), indicating that diffuse rather than focal brain injury results in instantaneous brain death in most victims of TCA. Brain surgery was attempted in none of them because of lack of recovery in the brainstem functions. Furthermore, CT evidence of hypoxic brain injury was present in another $39 \%$. In total, 35 (92\%) of the 38 TCA patients with ROSC sustained either traumatic or hypoxic brain injury (Fig. 1). The results that abnormal CT predicted fatality with a sensitivity of $95 \%$ and specificity of $100 \%$ show that brain CT is a reliable prognosticator in that population.

The frequency of UCSI, $34 \%$ in this study, seems to be compatible with those from postmortem radiological studies which range from $34 \%$ to $41 \%{ }^{1,6)}$ The axis is the vertebra most likely to be injured. ${ }^{1)}$ Concomitant TBI and USCI occurs relatively infrequently (Table 3), only in $13 \%$ in this study. Nevertheless, the frequency is higher than that of comatose TBI patients presenting with pulse, in whom concomitant USCI is present only in $3 \%$ to $4 \% .^{7,20)}$ Relatively high frequency of $\mathrm{AAD}$ and OAD (Fig. 3) in our series may explain the difference, although they are rarely present in comatose TBI patients presenting with pulse. Spine surgery was attempted in none of them because of lack of recovery in the brainstem functions. Like TBI, the presence of USCI on cervical spine CT also seems to reflect severe injury and predict fatality, although survival after fixation surgery has rarely been reported. ${ }^{12)}$

Despite potential benefits of CT in prognostication of patients with TCA achieving ROSC, there are not a few limitations in this study. Even when TBI and/ or spinal instability was found, the great majority of the patients remained clinically brain-dead, and obtaining CT may not help identify those with potentially operable lesions: in contrast to abnormal brain CT which invariably predicts fatality, intact CT may not be associated with long-term survival. Distinction between traumatic and hypoxic brain injury on brain CT may also be arbitrary. Diffuse axonal injury may not be visualized optimally on brain CT, ${ }^{17)}$ and several patients with this injury might have been classified either as hypoxic brain injury or intact. It should also be reminded that TCA is a clinical entity with heterogenous causes. Due to lack of autopsy, it is uncertain whether TBI visualized on brain CT was really responsible for fatality. Similarly, a small proportion of UCSI may also have been asymptomatic, and it is unclear whether all USCIs visualized on cervical spine CT were responsible for fatality.

We acknowledge that the low survival rate of $0.7 \%$ needs to be improved, and are considering implementation of ambulance with physicians (so-called doctor-car). ${ }^{14)}$ Deterioration of trauma patients with pulse into CA during transport occurs not uncommonly, and such prehospital intervention may help prevent such deterioration and also achieve earlier restoration of ROSC. Prehospital application of various imaging modalities has also been studied extensively in other countries and may be promising. Feasibility and efficacy of portable ultrasound at trauma scene has been demonstrated repeatedly. ${ }^{3)}$ More recently, an ambulance equipped with a portable CT unit has been introduced so that thrombolytic therapy for acute stroke patients can be initiated prehospitally. ${ }^{22)}$ Although such mobile CT may not be available soon in our country, prehospital acquisition of CT images in severe trauma patients has a potential to prolong their therapeutic time window: whole body CT may reveal occult bodily lesions for which early interventions may favorably alter the course of patients. After such progress in emergency diagnostic imaging, we expect that CT scans for patients with TCA may become meaningful not only as a prognostication tool but also in making treatment decision in the near future.

In conclusion, CT obtained immediately after resuscitation showed that more than $90 \%$ of TCA patients with ROSC had a CT evidence of traumatic and/or hypoxic brain injury, and the presence of abnormal brain CT predicted fatality with high sensitivity and specificity. USCI was present in $34 \%$, and the presence of USCI also seems to predict fatality. These results suggest that brain and cervical spine CT may be a valuable tool in the prognostication 
of TCA patients with ROSC.

\section{Conflicts of Interest Disclosure}

The authors have no personal, financial, or institutional interest in any of the drugs, materials, or devices described in this article.

\section{References}

1) Alker GJ, Oh YS, Leslie EV, Lehotay J, Panaro VA, Eschner EG: Postmortem radiology of head neck injuries in fatal traffic accidents. Radiology 114: 611-617, 1975

2) Amantini A, Amadori A, Fossi S: Evoked potentials in the ICU. Eur J Anaesthesiol Suppl 42: 196-202, 2008

3) Busch M: Portable ultrasound in pre-hospital emergencies: a feasibility study. Acta Anaesthesiol Scand 50: 754-758, 2006

4) Cera SM, Mostafa G, Sing RF, Sarafin JL, Matthews BD, Heniford BT: Physiologic predictors of survival in post-traumatic arrest. Am Surg 69: 140-144, 2003

5) Cocchi MN, Lucas JM, Salciccioli J, Carney E, Herman S, Zimetbaum P, Donnino MW: The role of cranial computed tomography in the immediate post-cardiac arrest period. Intern Emerg Med 5: 533-538, 2010

6) Dreiangel N, Ben-Galim P, Lador R, Hipp JA: Occipitocervical dissociative injuries: common in blunt trauma fatalities and better detected with objective computed tomography-based measurements. Spine J 10: 704-707, 2010

7) Holly LT, Kelly DF, Counelis GJ, Blinman T, McArthur DL, Cryer HG: Cervical spine trauma associated with moderate and severe head injury: incidence, risk factors, and injury characteristics. J Neurosurg 96 (3 Suppl): 285-291, 2002

8) Huber-Wagner S, Lefering R, Qvick M, Kay MV, Paffrath T, Mutschler W, Kanz KG; Working Group on Polytrauma of the German Trauma Society (DGU): Outcome in 757 severely injured patients with traumatic cardiorespiratory arrest. Resuscitation 75: 276-285, 2007

9) Huber-Wagner S, Lefering R, Qvick LM, Körner M, Kay MV, Pfeifer KJ, Reiser M, Mutschler W, Kanz KG: Working Group on Polytrauma of the German Trauma Society: Effect of whole-body CT during trauma resuscitation on survival: a retrospective, multicentre study. Lancet 373: 1455-1461, 2009

10) Inamasu J, Miyatake $S$, Tomioka $H$, Suzuki $M$, Nakatsukasa M, Maeda N, Ito T, Arai K, Komura M, Kase K, Kobayashi K: Subarachnoid haemorrhage as a cause of out-of-hospital cardiac arrest: a prospective computed tomography study. Resuscitation 80: 977-980, 2009

11) Inamasu J, Miyatake S, Suzuki $M$, Nakatsukasa $M$, Tomioka H, Honda M, Kase K, Kobayashi K: Early CT signs in out-of-hospital cardiac arrest survivors: Temporal profile and prognostic significance. Resus- citation 81: 534-538, 2010

12) Kleweno CP, Zampini JM, White AP, Kasper EM, McGuire KJ: Survival after concurrent traumatic dislocation of the atlanto-occipital and atlanto-axial joints: a case report and review of the literature. Spine 33: E659-E662, 2008

13) Martin SK, Shatney CH, Sherck JP, Ho CC, Homan SJ, Neff J, Moore EE: Blunt trauma patients with prehospital pulseless electrical activity (PEA): poor ending assured. J Trauma 53: 876-880; discussion 880-881, 2002

14) Matsumoto H, Mashiko K, Hara Y, Kutsukata N, Sakamoto Y, Takei K, Kanemaru K, Tomita Y, Saito $\mathrm{N}$, Yagi $\mathrm{T}$, Tetsu S, Iida $\mathrm{H}$, Masuda $\mathrm{Y}$, Koami $\mathrm{H}$, Yokota H: Role of resuscitative emergency field thoracotomy in the Japanese helicopter emergency medical service system. Resuscitation 80: 1270-1274, 2009

15) Naples R, Ellison E, Brady WJ: Cranial computed tomography in the resuscitated patient with cardiac arrest. Am J Emerg Med 27: 63-67, 2009

16) Pickens JJ, Copass MK, Bulger EM: Trauma patients receiving CPR: predictors of survival. J Trauma 58: 951-958, 2005

17) Provenzale J: CT and MR imaging of acute cranial trauma. Emerg Radiol 14: 1-12, 2007

18) Rosemurgy AS, Norris PA, Olson SM, Hurst JM, Albrink MH: Prehospital traumatic cardiac arrest: the cost of futility. J Trauma 35: 468-473; discussion 473-474, 1993

19) Shimazaki S, Yamaguchi Y, Murata A, Kobayashi K: [Postgraduate trauma education for surgeon-from the viewpoint of trauma and emergency physicians]. Nihon Geka Gakkai Zasshi 104: 290-293, 2003 [Japanese]

20) Tian HL, Guo Y, Hu J, Rong BY, Wang G, Gao WW, Chen SW, Chen H: Clinical characterization of comatose patients with cervical spine injury and traumatic brain injury. J Trauma 67: 1305-1310, 2009

21) Torbey MT, Selim M, Knorr J, Bigelow C, Recht L: Quantitative analysis of the loss of distinction between gray and white matter in comatose patients after cardiac arrest. Stroke 31: 2163-2167, 2000

22) Walter S, Kostopoulos P, Haass A, Keller I, Lesmeister M, Schlechtriemen T, Roth C, Papanagiotou P, Grunwald I, Schumacher H, Helwig S, Viera J, Körner H, Alexandrou M, Yilmaz U, Ziegler K, Schmidt K, Dabew R, Kubulus D, Liu Y, Volk T, Kronfeld K, Ruckes C, Bertsch T, Reith W, Fassbender K: Diagnosis and treatment of patients with stroke in a mobile stroke unit versus in hospital: a randomised controlled trial. Lancet Neurol 11: 397-404, 2012

Address reprint requests to: Joji Inamasu, MD, FACS, Department of Neurosurgery, Fujita Health University Hospital, 1-98 Kutsukake, Toyoake, Aichi 470-1131, Japan. e-mail: inamasu@fujita-hu.ac.jp 